\title{
Re-establishing Apoptosis
} Competence in Bone Associated Cancers via Communicative Reprogramming Induced Through Notch Signaling Inhibition

\author{
Michela Colombo ${ }^{1+}$, Natalia Platonova ${ }^{1+}$, Domenica Giannandrea1, \\ Maria Teresa Palano ${ }^{1}$, Andrea Basile ${ }^{2}$ and Raffaella Chiaramonte ${ }^{1 *}$ \\ ${ }^{1}$ Department of Health Sciences, University of Milan, Milan, Italy, ${ }^{2}$ Department of Oncology and Hemato-Oncology, \\ University of Milan, Milan, Italy
}

\section{OPEN ACCESS}

Edited by:

Lina Ghibelli,

University of Rome Tor Vergata, Italy

\section{Reviewed by: \\ Mauro Krampera, \\ University of Verona, Italy \\ Erina Vlashi,}

University of California, Los Angeles,

United States

*Correspondence:

Raffaella Chiaramonte

raffaella.chiaramonte@unimi.it

${ }^{\dagger}$ These authors have contributed equally to this work

Specialty section:

This article was submitted to

Experimental Pharmacology

and Drug Discovery,

a section of the journal

Frontiers in Pharmacology

Received: 20 December 2018

Accepted: 06 February 2019

Published: 27 February 2019

Citation:

Colombo M, Platonova N, Giannandrea D, Palano MT, Basile A

and Chiaramonte $R$ (2019)

Re-establishing Apoptosis

Competence in Bone Associated

Cancers via Communicative

Reprogramming Induced Through

Notch Signaling Inhibition.

Front. Pharmacol. 10:145.

doi: 10.3389/fphar.2019.00145
Notch and its ligands on adjacent cells are key mediators of cellular communication during developmental choice in embryonic and adult tissues. This communication is frequently altered in the pathological interaction between cancer cells and healthy cells of the microenvironment due to the aberrant expression of tumor derived Notch receptors or ligands, that results in homotypic or heterotypic Notch signaling activation in tumor cells or surrounding stromal cells. A deadly consequence of this pathological communication is pharmacological resistance that results in patient's relapse. We will provide a survey of the role of Notch signaling in the bone marrow (BM), a microenvironment with a very high capacity to support several types of cancer, including primary cancers such as osteosarcoma or multiple myeloma and bone metastases from carcinomas. Moreover, in the BM niche several hematological malignancies maintain a reservoir of cancer stem cells, characterized by higher intrinsic drug resistance. Cell-cell communication in BM-tumor interaction triggers signaling pathways by direct contact and paracrine communication through soluble growth factors or extracellular vesicles, which can deliver specific molecules such as mRNAs, miRNAs, proteins, metabolites, etc. enabling tumor cells to reprogram the healthy cells of the microenvironment inducing them to support tumor growth. In this review we will explore how the dysregulated Notch activity contributes to tumor-mediated reprogramming of the BM niche and drug resistance, strengthening the rationale of a Notch-directed therapy to re-establish apoptosis competence in cancer.

Keywords: Notch, Jagged, DII, apoptosis, drug resistance, metabolism, stem cell, anakoinosis

Abbreviations: ALDH, aldehyde dehydrogenase; ALDOA, aldolase A; AML, acute myeloid leukemia; B-ALL, B-cell acute lymphoblastic leukemia; BM, bone marrow; BMSCs, bone marrow stromal cells; CLL, chronic lymphocytic leukemia; CML, chronic myeloid leukemia; CSCs, cancer stem cells; EMT, epithelial-mesenchymal transition; ENO1,2, enolase1,2; GSI-XII, gamma-secretase inhibitor XII; HK2, hexokinase 2; ICN, intracellular portion of Notch; LDHA, lactate dehydrogenase A; LSCs, leukemic stem cells; MGUS, monoclonal gammopathy of uncertain significance; MM, multiple myeloma; NSCLs, non-small cell lung cancer; OBL, osteoblast; OS, osteosarcoma; OXPHOS, oxidative phosphorylation; PDK2, pyruvate dehydrogenase kinase 2; PFKM, phosphofructokinase muscle type; ROS, reactive oxygen species; T-ALL, T-cell acute lymphoblastic leukemia; TCA, tricarboxylic acid. 


\section{INTRODUCTION}

Bone marrow $(\mathrm{BM})$ is a supportive milieu for primary cancers including osteosarcoma (OS) or multiple myeloma (MM), derived from BM osteoblasts (OBLs) or resident plasma cells, but also hematological cancers that maintain a reservoir of cancer stem cells (CSCs) in the BM niche (Crews and Jamieson, 2012; Behrmann et al., 2018) and bone metastases from carcinomas (Mundy, 2002; Coleman, 2006). Bone localization is critical. Indeed, up to $85 \%$ of patients that die from breast, prostate, or lung cancer display bone involvement at autopsy (Mundy, 2002; Coleman, 2006).

Bone associated cancers share the propensity to colonize the $\mathrm{BM}$ and take advantage of this specialized niche that favors tumor growth and induces pharmacological resistance. Here, cancer cells establish a pathological communication with nearby cells, such as stromal and bone cells, inducing the release of pro-tumor factors and cytokines (Kan et al., 2016; Colombo et al., 2018).

Notch pathway mediates cell-cell communication during cell fate decisions involved in embryonic development or adult tissues renewal (Siebel and Lendahl, 2017). Notch pathway is composed of a family of Notch receptors, Notch1-4, and two families of ligands, Jagged1, 2 and Dll1,3,4 (Figure 1A) (Platonova et al., 2017a). As illustrated by Figure 1B, Notch ligands bind to their receptors on adjacent cells inducing the release of the activated intracellular portion of Notch (ICN). ICN translocates into the nucleus and binds the RBJK/CSL complex triggering the transcription of target genes involved in proliferation, survival, differentiation and stemness (Platonova et al., 2017a). These include the HES (Kageyama et al., 2007) and HEY (Weber et al., 2014) families of transcriptional repressor genes, $c-M y c$ (Sato et al., 2016), cyclin-D1 (Ronchini and Capobianco, 2001), p21 (Rangarajan et al., 2001), genes of NF- $\kappa$ B pathway such as RELB and NFKB2 (Vilimas et al., 2007), and other genes which regulate the biological functions altered in cancer.

Additionally, non-canonical Notch signaling can occur independently from RBJK/CSL and dependently or not from ligand interaction. This exerts its biological functions interacting with other key signaling pathways,

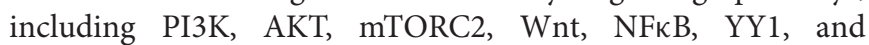
HIF-1 $\alpha$, at cytoplasmic and/or nuclear levels (MacKenzie et al., 2004; Sade et al., 2004; Perumalsamy et al., 2009; Ayaz and Osborne, 2014; Platonova et al., 2015).

Due to the key role of Notch signaling in cellular communication, it is not surprising that its deregulation favors the pathological communication between cancer cells and BM cells.

This review represents a survey on Notch signaling activity in tumor-mediated reprogramming of the BM niche with the final purpose to provide evidence that dysregulated Notch pathway members may be rational therapeutic targets to re-establish apoptosis competence in cancer cells.

Here, we will focus on the ability of the reprogrammed $\mathrm{BM}$ niche to increase tumor cell resilience to chemotherapeutic agents, exploring the three main ways of BM cells involvement: (1) increasing the anti-apoptotic background of cancer cells;
(2) inducing the glycolytic switch of tumor cells; (3) increasing the amount of CSCs.

\section{NOTCH PROMOTES BM-MEDIATED INCREASE OF ANTI-APOPTOTIC BACKGROUND IN CANCER CELLS}

Canonical and non-canonical notch pathway plays an acknowledged role in the regulation of apoptosis (MacKenzie et al., 2004; Sade et al., 2004; Perumalsamy et al., 2009; Platonova et al., 2015). Aberrant Notch signaling triggers anti-apoptotic program and drug resistance in different types of tumors, such as T-ALL (Sade et al., 2004), B-ALL (Nwabo Kamdje et al., 2011), CLL (Nwabo Kamdje et al., 2012), AML (Takam Kamga et al., 2016), Hodgkin and anaplastic large cell lymphoma (Jundt et al., 2002), cervical cancer cells (Perumalsamy et al., 2009), breast cancer (Meurette et al., 2009), MM (Nefedova et al., 2008; Mirandola et al., 2013; Ding and Shen, 2015; Garavelli et al., 2017), colon cancer (Meng et al., 2009), OS (Ma et al., 2013; Pu et al., 2017).

Figure 1C illustrates that Notch may be activated in tumor cells, but also in BM stromal cells (BMSCs) stimulating them to promote drug resistance. Indeed, BMSCs express Notch ligands, i.e., Jagged1, Jagged2 and Dll1, Dll3, and receptors, i.e., Notch1 and Notch2 (Bertrand et al., 2000; Nefedova et al., 2004; Xu et al., 2012a,b; Jitschin et al., 2015; Colombo et al., 2016; Sato et al., 2016), and many lines of evidence indicate that BMSC-derived Notch ligands may trigger Notch signaling in tumor cells inducing drug resistance. Krampera's group widely demonstrated that Notch signaling activated by BMSCs promotes cell survival and chemoresistance in lymphoid neoplasms such as CLL [resistance to fludarabine, cyclophosphamide, bendamustine, prednisone, and hydrocortisone (Nwabo Kamdje et al., 2012)], B-ALL [resistance to hydrocortisone (Nwabo Kamdje et al., 2011)] and AML [resistance to cytarabine, idarubicin, and etoposide (Takam Kamga et al., 2016)] by increasing anti-apoptotic proteins including c-IAP2, Bcl-2, and NF- $\kappa \mathrm{B}$ and reducing PARP and the active form of Caspase3 (Nwabo Kamdje et al., 2011, 2012; Takam Kamga et al., 2016). Consistently, Notch depletion, induced by specific antibodies or $\gamma$-secretase inhibitor XII (GSI XII), reverted the protective effect of BMSCs (Nwabo Kamdje et al., 2011, 2012; Takam Kamga et al., 2016).

Notch signaling mediates also the pathological communications between BMSCs and MM cells promoting tumor cell survival and development of drug resistance (Colombo et al., 2013). MM cells accumulate in the BM, where they establish complex interactions with the surrounding healthy cells stimulating the release of anti-apoptotic factors relevant in drug resistance (Colombo et al., 2015a).

In the myelomatous BM, Notch signaling may be activated by a bilateral communication both in $\mathrm{MM}$ cells and in BM cells. Indeed, as reported for other hematological malignancies, BMSC-derived Notch ligands may activate Notch signaling by triggering Notch1 and Notch2 in myeloma cell (Colombo et al., 2013; Muguruma et al., 2017). 
BMSC-mediated Notch signaling activation has different outcomes, including the upregulation of $\mathrm{p} 21^{\mathrm{Cip} 1 / \mathrm{WAF} 1}$ and the downregulation of the pro-apoptotic protein NOXA in a p53-independent way (Nefedova et al., 2004, 2008).
These, in turn, result in cell cycle slowdown and apoptosis resistance that protects tumor cells from apoptosis induced by chemotherapeutic drugs, such as doxorubicin, melphalan and mitoxantrone (Nefedova et al., 2004; Muguruma et al., 2017).
A

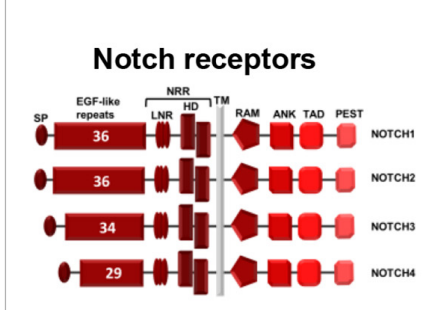
The families of Notch
ligands

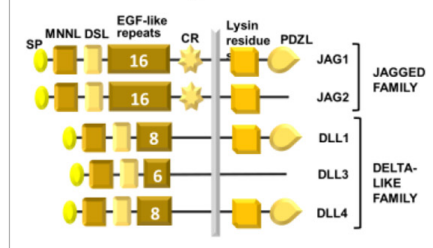

B

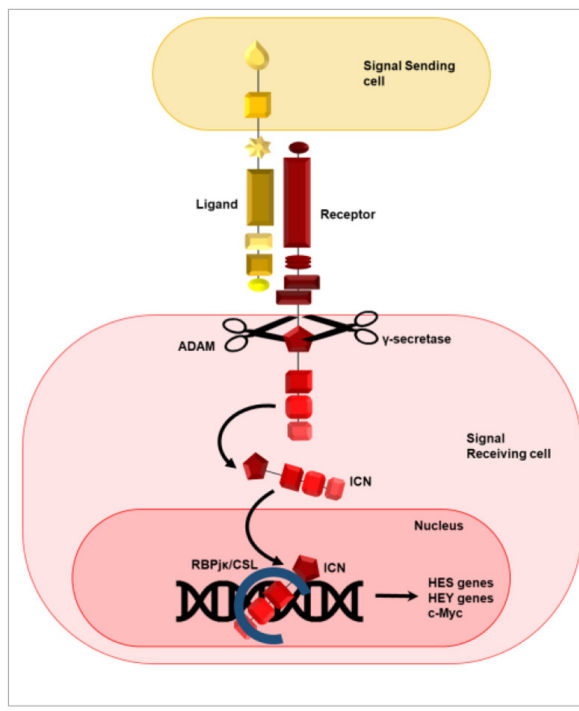

C

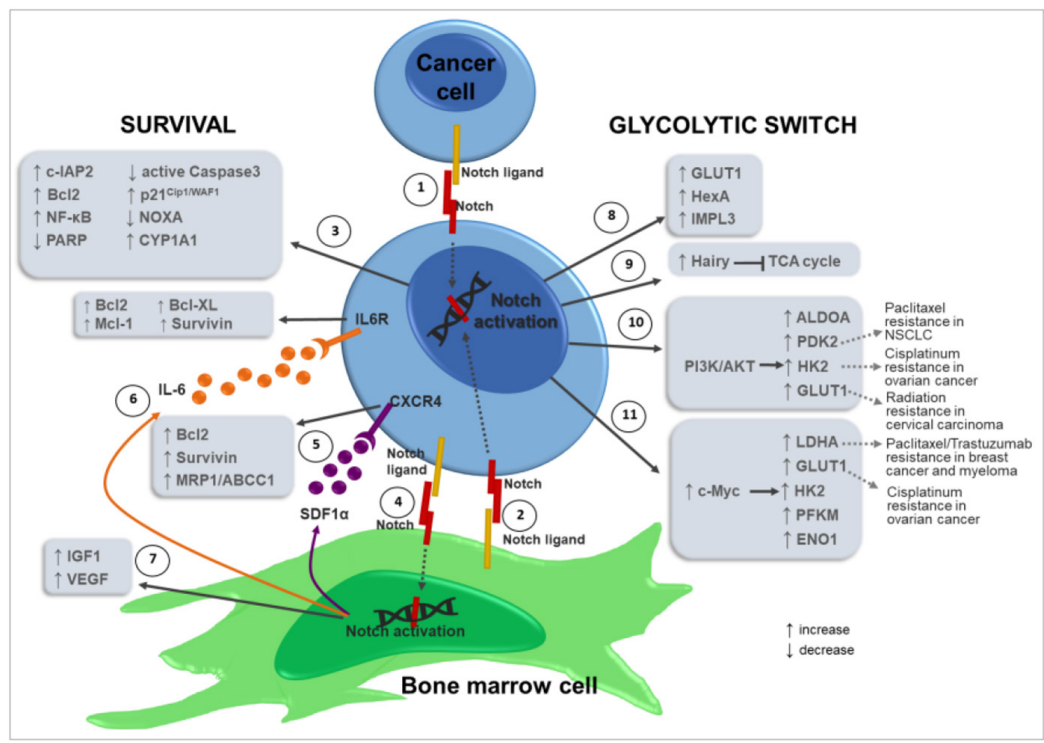

D

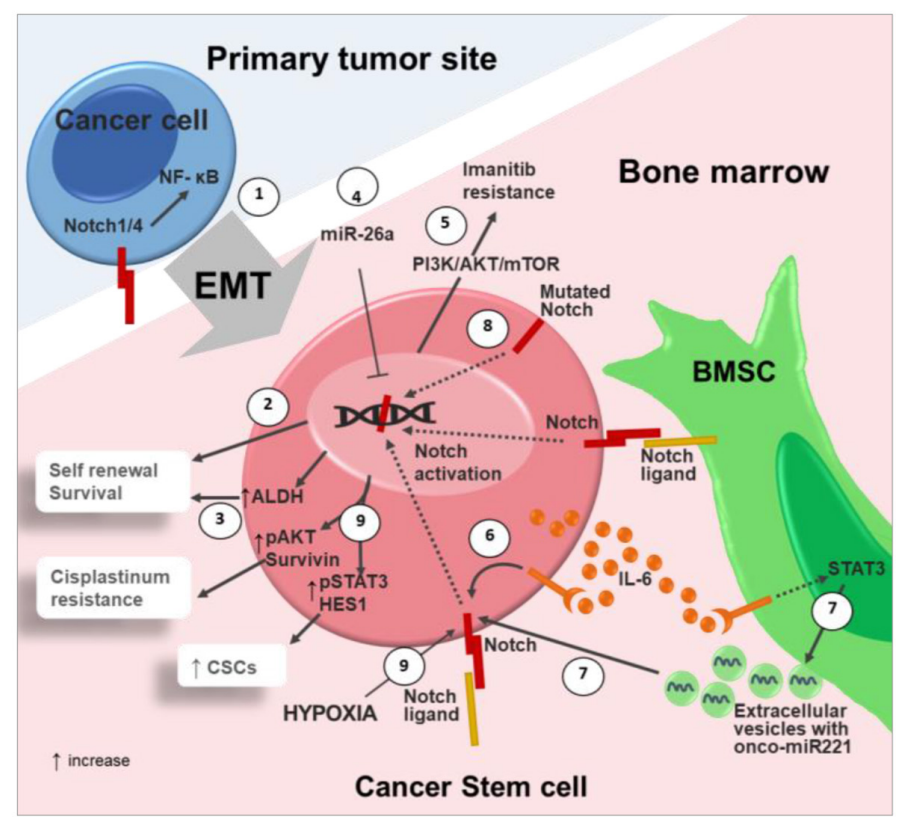

FIGURE 1 | Notch pathway promotes drug resistance by regulating cancer cell survival, glycolytic switch and cancer stem cells. (A) Notch pathway can be triggered by the interaction of 4 receptors (Notch1-4) and 2 different classes of ligands, named Jagged (Jagged1-2) and Delta-like family (DII1-3-4) (Platonova et al., 2015, 2017a,b). The following domains can be distinguished in Notch receptors: signal peptide (SP); epidermal growth factor(EGF)-like repeats; Negative Regulatory Region (NRR), composed by Lin-Notch repeats (LNR) and heterodimerization domain (HD); transmembrane domain (TM); RBJK associated module (RAM); ankyrin repeats (ANK); transactivation domain (TAD); proline(P), glutamic acid(E),serine(S) and threonine (T) domain (PEST). Jagged and DIl ligands are composed by: signal peptide (SP); Notch ligand N-terminal domain (MNNL); Delta/Serrate/LAG-2 domain (DSL); epidermal growth factor(EGF)-like repeats; cysteine rich region (CR); transmembrane domain (TM); Lysin residues; (PSD-95/Dlg/ZO-1)-ligand motif (PDZL) (Platonova et al., 2017a,b). (B) Canonical Notch signaling: Notch activation is 


\section{FIGURE 1 | Continued}

triggered by ligand engagement which enables two consecutive proteolytic cleavages performed by the ADAM metalloproteinase and the $\gamma$-secretase complex, that allow ICN to translocate into the nucleus where it binds the RBJK/CSL complex and activates the transcription of Notch target genes such as the HES (Kageyama et al., 2007), and HEY (Weber et al., 2014) family of genes, C-Myc (Sato et al., 2016) and other genes involved in proliferation, survival, differentiation and stemness. (C) Notch role in cancer cell drug resistance. Notch activation in cancer cell can occur through: (1) homotypic interaction with nearby cancer cells or (2) heterotypic interaction with BM cells (i.e., BMSC). (3) Notch ligands localized on the surface of BMSCs activate Notch signaling in tumor cells resulting in increased expression of anti-apoptotic proteins including c-IAP2, Bcl-2, NF-kB and decreased expression of PARP and active Caspase3 (Nwabo Kamdje et al., 2011, 2012; Takam Kamga et al., 2016) with the subsequent development of chemoresistance mechanisms in different tumors as CLL (Nwabo Kamdje et al., 2012), B-ALL (Nwabo Kamdje et al., 2011) and AML (Takam Kamga et al., 2016). Moreover, BMSC-derived Notch ligands may stimulate the expression of p21 Cip1/WAF1 and CYP1A1 and downregulate pro-apoptotic NOXA in cancer cells via Notch signaling regulating the development of drug resistance in MM cells (Nefedova et al., 2004, 2008; Xu et al., 2012a,b). (4) On the other hand, also cancer cells may activate Notch signaling in BM cells such as BMSCs, that in turn secrete the following pro-tumoral soluble factors: (5) SDF1 $\alpha$ promotes and upregulates Bcl-2, Survivin and MRP1/ABCC1 in MM (Garavelli et al., 2017); (6) IL6 (Colombo et al., 2016) is reported to upregulate anti-apoptotic and pro-survival proteins in tumor cells including Bcl-2, Mcl-1, Bcl-X, and Survivin (Catlett-Falcone et al., 1999; Shain et al., 2009; Ara and Declerck, 2010); (7) IGF1 and VEGF can contribute to induce drug resistance in hematological and solid tumors (Dias et al., 2002; Belcheva et al., 2004; Zhang et al., 2006; Kuhn et al., 2012; Hua et al., 2014; Nusrat et al., 2016; Bendardaf et al., 2017). Notch pathway may influence tumor cell drug sensitivity also promoting the glycolytic switch by enhancing the expression of glucose transporters and glycolytic enzymes in cancer cells. (8) In $D$. melanogaster Notch signaling was found to regulate GLUT1, HexA and IMPL3 and (9) suppress TCA cycle via the upregulation of Hairy gene (Slaninova et al., 2016). (10) In breast cancer Notch signaling induces PI3K/AKT activation that leads to the upregulation of glycolytic enzymes such as ALDOA, PDK2, HK2, and GLUT1 (Landor et al., 2011). Notably, BM adipocytes enhance the expression of two acknowledged Notch downstream effectors, i.e., HK2 and GLUT1, in prostate cancer cells (Diedrich et al., 2016). (11) In CLL, Notch pathway activation induces c-Myc upregulation and the subsequent increased expression of LDHA, GLUT1, HK2, PFKM, and ENO1 (Dang et al., 2009 ). Finally, wherever possible, for each Notch downstream effector involved in cancer cell glycolytic switch, it is reported the recognized outcome in drug and radiation resistance (Zhao et al., 2011; Huang et al., 2014; Lin et al., 2015; Sun et al., 2017; Zhang et al., 2018). (D) Notch in cancer stem cells: (1) Notch signaling promotes cancer cell EMT, which is closely associated to stemness. For instance, Notch1 and Notch4 expression in prostate cancer cells promotes EMT via NF-кB activation. EMT also enables cancer cell dissemination throughout the body including BM (Shibue and Weinberg, 2017; Zhang L. et al., 2017; Lin et al., 2018). (2) At BM level, Notch pathway activation in CSCs can be mediated by homotypic or heterotypic interactions and positively regulates tumor cell self-renewal, resulting in the amplification of the CSC population characterized by intrinsic high pharmacological resistance. (3) In OS cell, Notch activation boosts the expression of ALDH (Mu et al., 2013), a CSC marker also associated with drug resistance due to its detoxifying activity (Honoki et al., 2010). (4) miR-26a inhibits self-renewal by down-regulating Jagged1/Notch signaling (Lu J. et al., 2017). (5) In CLL, Notch activation results in resistance to Imatinib mediated by PI3K/AKT/mTOR signaling (Aljedai et al., 2015). (6) In BM microenvironment, tumor-derived IL-6 promotes an autocrine upregulation of Notch3, that in turn supports CSC survival and self-renewal (Sansone et al., 2016). (7) Moreover, IL-6 triggers STAT3 signaling in BMSCs improving the secretion of extracellular vesicles carrying the onco-miR221; this, in turn, increases Notch3 expression in CSCs and hormonal therapy resistance in bone metastasis of luminal breast cancer (Sansone et al., 2017). (8) In NSCLC, activating mutations of Notch1 correlate with CSCs and poor prognosis in patients (Westhoff et al., 2009). (9) In NSCLC, hypoxia-induced Notch1 activation promotes CSC self-renewal via PSTAT3 and HES1 and cis-platinum resistance through the positive regulation of PAKT and Survivin (Zhang Y. et al., 2017).

Consistently, GSI-mediated inhibition of Notch signaling in $\mathrm{MM}$ cells significantly improved the response of MM cells to standard chemotherapy. In accordance, $\mathrm{Xu}$ et al. (2012a) demonstrated that BMSC-derived Dll1 activates Notch pathway in MM cells determining bortezomib resistance by upregulating CYP1A1, a member of the cytochrome P450 family involved in drug metabolism. In line with these data, the combined treatment of the syngeneic 5T33MM murine model with bortezomib and GSI resulted in increased bortezomib sensitivity and overall survival (Xu et al., 2012a).

In $\mathrm{MM}$, the direction of the pathological communication may also be from tumor cells to BMSCs. Indeed, MM cells are reported to express Jagged ligands since the earlier stages. Jagged2 expression is already detectable in the benign form of MGUS and increases with disease progression (Houde et al., 2004), while Jagged 1 increases during the progression from MGUS to MM (Skrtic et al., 2010). We used human MM cell lines, primary MM patients' cells and a zebrafish MM model to show that MM cell-derived Jagged1 and 2 are pivotal to promote tumor cell ability to reprogram the nearby $\mathrm{BM}$ niche, and specifically to trigger BMSCs to protect MM cells from apoptosis induced by bortezomib, lenalidomide, and melphalan (Garavelli et al., 2017). The outcome of Notch signaling activation in BMSCs is the increased secretion of key cytokines, among which IL-6, IGF1, SDF1 $\alpha$, and VEGF (Houde et al., 2004; Colombo et al., 2014, 2016;
Garavelli et al., 2017). These soluble molecules contribute to create a microenvironment favorable to tumor growth by regulating key biological processes such as cell survival and resistance to cytotoxic chemotherapy. Indeed, we showed that SDF1 $\alpha$, released by BMSCs upon MM-derived Jagged stimulation, determines MM cell resistance to the above reported drugs by promoting the expression of $\mathrm{Bcl} 2$, survivin and the multidrug resistance-associated protein 1 (MRP1/ABCC1) (Garavelli et al., 2017). IL-6 is widely involved in drug resistance induced by microenvironment. In MM cells IL6 activates STAT3 signaling and increases the expression of antiapoptotic genes, such as Bcl2, Bcl- $\mathrm{X}_{\mathrm{L}}$, Mcl-1, and survivin, commonly associated with chemoresistance (Catlett-Falcone et al., 1999; Shain et al., 2009; Ara and Declerck, 2010). IGF1 has been reported to promote MM cell resistance to bortezomib (Kuhn et al., 2012).

Although there is still no evidence concerning a role of VEGF signaling in MM drug resistance, it confers chemoresistance in several types of solid and hematological tumors (Dias et al., 2002; Belcheva et al., 2004; Zhang et al., 2006; Hua et al., 2014; Nusrat et al., 2016; Bendardaf et al., 2017) and involves antiapoptotic effectors that play a role also in MM-associated drug resistance such a as Bcl2 and survivin (Gerber et al., 1998; Tran et al., 2002).

Similarly to MM cells, also bone metastatic breast cancer cells expressing high levels of Jagged1 activate Notch signaling in OBLs, thus stimulating the secretion of IL-6 
that, in turn, favors tumor growth and chemoresistance (Sethi et al., 2011). On the other side, although the recognized role played by Notch signaling in OS pathogenesis (McManus et al., 2014; Tao et al., 2014) and multidrug resistance (Ma et al., 2013; Pu et al., 2017), it has not been established yet whether the underlying mechanism involves exclusively a tumor cell autonomous activation of Notch mediated by the high Dll1 level or if it may include also an increased Notch activity in the surrounding cells. Indeed, $\mathrm{Pu}$ et al. (2017) found that miR-34a-5p promotes OS multi-chemoresistance via repression of Dll1, indicating that targeting miR-34a-5p and Dll1 may provide a valuable strategy to overcome OS chemoresistance.

\section{BONE MARROW MAY PROMOTE DRUG RESISTANCE BY ACTIVATING THE GLYCOLYTIC SWITCH IN TUMOR CELLS VIA NOTCH SIGNALING}

Cancer cells may promote survival and proliferation by changing their metabolism, most frequently by increasing the glucose intake and consumption. In mammals, glucose is used for ATP production through glycolysis, TCA cycle and the OXPHOS in mitochondria. An aberrant feature of cancer cells is a significant increase of glucose uptake mainly exploited through glycolysis even in the presence of oxygen and intact mitochondria ( $\mathrm{Lu}$ et al., 2015). This phenomenon is known as Warburg effect and recent studies indicate that it influences tumor cell drug sensitivity by enhancing drug efflux, DNA damage repair, survival and autophagy (Koppenol et al., 2011). Thereby, the onset of drug resistance is frequently associated with the upregulation of glycolytic key players including the glucose transporters and glycolytic enzymes (Butler et al., 2013). For instance, the upregulation of the glucose transporter 1 (GLUT1) is correlated with radiation resistance and poor prognosis in cervical squamous cell carcinoma patients (Huang et al., 2014; Lin et al., 2015). The increased expression of pyruvate kinase muscle isozyme 2 (PKM2) has been linked with resistance to Epirubicin and 5-fluorouracil in breast cancer patients (Lin et al., 2015), while its silencing potentiates the effects of oxaliplatin in colorectal cancer cells (Lu W.Q. et al., 2017). LDHA is associated with breast cancer resistance to paclitaxel/trastuzumab and myeloma relapse (Zhao et al., 2011); overexpression of hexokinase 2 (HK2) is involved in cisplatin resistance in ovarian cancer cells, by enhancing autophagy (Zhang et al., 2018) and the increased expression of PDK2 is linked to paclitaxel resistance in NSCLC (Sun et al., 2017).

The glycolytic switch in cancer cells is due to the activation of molecular pathways involved in the transcriptional regulation of several metabolic genes, among which the Notch signaling pathway (Figure 1C). Notch involvement was initially reported in Drosophila melanogaster, where it positively regulates genes encoding for Glut1, glycolytic enzyme hexokinase A (Hex-A), LDHA (Ecdysone-inducible gene L3, Impl3) and inhibits TCA cycle by upregulating the gene Hairy, which binds to the regulatory regions of TCA genes [Sdhb, 1(1)G0255 and $\mathrm{Kdn}$ ] suppressing their transcription (Slaninova et al., 2016).

Therefore, it is not surprising that Notch signaling dysregulation in cancer cells may also alter their metabolism. This effect has been mainly explored in breast cancer cells. Here, Notch activation may be induced by PEST mutations in Notch1-3 (Wang et al., 2015), high expression levels of Notch1, 3, 4, Jagged1, and Dll4 (Lamy et al., 2017; Kontomanolis et al., 2018), and BM-derived Notch ligands such as Jagged1 (Sethi et al., 2011; Zheng et al., 2017). In vitro and in vivo studies indicate that, in breast cancer, Notch signaling activation leads to increased glycolysis through the activation of the PI3K/AKT pathway, resulting in the upregulation of GLUT1 expression and genes for rate-limiting glycolytic enzymes such as $H K 2$, $A L D O A$ and PDK2. Notch activation also induces GLUT1 translocation from cytoplasmic to membrane localization consistently with an increased glucose uptake due to glycolytic switch (Landor et al., 2011).

Recent evidence indicates that Notch pathway can participate also in the BMSC-induced metabolic switch. Indeed BMSCderived Jagged 1 plays an important role by favoring breast cancer bone metastasis formation and drug resistance (Sethi et al., 2011) and Landor et al. (2011) recently reported that Jagged1-mediated Notch activation in MCF7 cells promotes glucose consumption.

The role of $\mathrm{BM}$ stromal microenvironment in promoting the switch of malignant cells from mitochondrial respiration to glycolysis along with the acquisition of chemoresistance is recognized in different other tumor types. For instance, BMSCs induce the glycolytic switch in ALL (Frolova et al., 2012) and CLL cells (Vangapandu et al., 2017), promoting resistance to standard of care drugs including vincristine, methotrexate, and etoposide. Similarly, primary marrow fat cells and adipocyte cell lines trigger metabolic reprogramming of bone metastatic prostate cancer cells by enhancing the expression of PDK1, enolase 2 (ENO2), LDHA as well as HK2 and GLUT1 (Diedrich et al., 2016), already mentioned as Notch downstream effectors in breast cancer cells (Landor et al., 2011).

The role of Notch in energy metabolism has been explored also in CLL. Here, gain-of-function mutations of Notch1 [ 80\% patients (Rosati et al., 2018)] stimulate a significant increase of glycolytic parameters (Jitschin et al., 2015). On the other hand, the activation of the four Notch isoforms expressed in CLL cells (Rosati et al., 2018) may be triggered also by BMSCderived Notch ligands, i.e., Jagged 1 and 2 and Dll3 (Jitschin et al., 2015). Consistently, BMSCs significantly increase the expression of glycolytic enzymes and glycolytic capacity. This effect is, at least in part, due to the promotion of Notch transcriptional activity on one of its most important targets, c-Myc that plays a recognized role in cancer cell energy metabolism by promoting the expression of LDHA, GLUT1, HK2, PFKM and ENO1 (Dang et al., 2009). In accordance, GSI-mediated inhibition of Notch significantly increases CLL 
TABLE 1 | Summary of the mechanisms involved in Notch pathway ability to promote BM reprogramming and drug resistance.

\begin{tabular}{|c|c|c|c|c|c|c|}
\hline Cancer type & Drug & $\begin{array}{l}\text { Notch pathway } \\
\text { members }\end{array}$ & Inhibitor tested & $\begin{array}{l}\text { Cellular } \\
\text { mechanism }\end{array}$ & $\begin{array}{l}\text { Molecular } \\
\text { mediators }\end{array}$ & Reference \\
\hline B-CLL & $\begin{array}{l}\text { Fludarabine } \\
\text { Cyclophosphamide } \\
\text { Bendamustine } \\
\text { Prednisone } \\
\text { Hydrocortisone } \\
\text { Ibrutinib }\end{array}$ & Notch1,2,4 & $\begin{array}{l}\text { GSI-XII } \\
\text { Combination of } \\
\text { anti-Notch1,2,4 } \\
\text { antibodies }\end{array}$ & $\begin{array}{l}\text { Resistance to } \\
\text { apoptosis; } \\
\text { BMSC-induced } \\
\text { glycolytic switch }\end{array}$ & $\begin{array}{l}\text { c-IAP2 Bcl-2 NF-кB } \\
\text { PARP c-myc cyclin } \\
\text { b1 }\end{array}$ & $\begin{array}{l}\text { Nwabo Kamdje } \\
\text { et al., 2012; } \\
\text { Jitschin et al., } \\
\text { 2015; Secchiero } \\
\text { et al., } 2017\end{array}$ \\
\hline B-ALL & Hydrocortisone & Notch3,4 & $\begin{array}{l}\text { GSI-XII } \\
\text { anti-Notch3,4 } \\
\text { Jagged1,2 and DII4 } \\
\text { antibodies }\end{array}$ & $\begin{array}{l}\text { Resistance to } \\
\text { apoptosis }\end{array}$ & $\mathrm{Bcl}-2$ & $\begin{array}{l}\text { Nwabo Kamdje } \\
\text { et al., } 2011\end{array}$ \\
\hline AML & $\begin{array}{l}\text { Cytarabine } \\
\text { Idarubicin } \\
\text { Etoposide }\end{array}$ & Unknown & GSI-IX GSI-XII & $\begin{array}{l}\text { Resistance to } \\
\text { apoptosis }\end{array}$ & STAT3, AKT NF-кB & $\begin{array}{l}\text { Takam Kamga } \\
\text { et al., } 2016\end{array}$ \\
\hline CML & Imatinib & $\begin{array}{l}\text { Notch1 Notch2 } \\
\text { HES1 }\end{array}$ & GSI-953 & $\uparrow L S C$ & PI3K-Akt/mTOR & Aljedai et al., 2015 \\
\hline MM & $\begin{array}{l}\text { Doxorubicin } \\
\text { Mitoxantrone } \\
\text { Bortezomib } \\
\text { Melphalan } \\
\text { Lenalidomide }\end{array}$ & Jagged1 Jagged2 & $\begin{array}{l}\text { GSI-XII Jagged } 1 / 2 \\
\text { siRNAs }\end{array}$ & $\begin{array}{l}\text { Resistance to } \\
\text { apoptosis; } \downarrow \text { BM } \\
\text { support } \uparrow \text { CSC }\end{array}$ & $\begin{array}{l}\text { p21 NOXA Bcl2 } \\
\text { Survivin ABCC1 } \\
\text { CXCR4 CYP1A1 }\end{array}$ & $\begin{array}{l}\text { Nefedova et al., } \\
\text { 2004, 2008; Chiron } \\
\text { et al., 2012; Xu } \\
\text { et al., 2012a; } \\
\text { Garavelli et al., } \\
\text { 2017; Muguruma } \\
\text { et al., } 2017\end{array}$ \\
\hline Osteo-sarcoma & $\begin{array}{l}\text { Dox Etoposide } \\
\text { Methotrexate } \\
\text { CDDP }\end{array}$ & Dll1 Jagged1 & - & $\begin{array}{l}\text { Resistance to } \\
\text { apoptosis; } \\
\uparrow \text { detoxifying } \\
\text { activity; } \uparrow \text { CSC }\end{array}$ & $\begin{array}{l}\text { miR34a-5p } \\
\text { ATF2/3/4 miR26a } \\
\text { ALDH }\end{array}$ & $\begin{array}{l}\text { Honoki et al., 2010; } \\
\text { Mu et al., 2013; } \\
\text { Macedo et al., } \\
\text { 2017; Pu et al., } \\
2017\end{array}$ \\
\hline Prostate cancer & - & Notch1 Notch4 & $\begin{array}{l}\text { Notch1 or Notch4 } \\
\text { siRNA }\end{array}$ & $\uparrow C S C \uparrow E M T$ & $\mathrm{NF} F_{\kappa} \mathrm{B}$ & $\begin{array}{l}\text { Zhang L. et al., } \\
\text { 2017; Lin et al., } \\
2018\end{array}$ \\
\hline Breast cancer & Lapatinib HT & $\begin{array}{l}\text { Notch1 Notch3 } \\
\text { Notch4 Jagged1 }\end{array}$ & $\begin{array}{l}\text { GSI-IX DBZ Notch1 } \\
\text { or Notch4 siRNA }\end{array}$ & $\begin{array}{l}\uparrow \mathrm{CSC} \uparrow \text { bone } \\
\text { resorption }\end{array}$ & $\begin{array}{l}\text { IL6/STAT3/ } \\
\text { oncomiR221 }\end{array}$ & $\begin{array}{l}\text { Harrison et al., } \\
\text { 2010b; Sansone } \\
\text { et al., 2016; Zheng } \\
\text { et al., 2017; Shah } \\
\text { et al., } 2018\end{array}$ \\
\hline NSCLC & Cisplatinum & Notch1 & RO4929097 & $C S C$ hypoxia & STAT3 AKT Survivin & $\begin{array}{l}\text { Zhang L. et al., } \\
2017\end{array}$ \\
\hline
\end{tabular}

cell sensibility to used drugs, including Fludarabine and Ibrutinib (Jitschin et al., 2015; Secchiero et al., 2017).

The ability of Notch signaling to potentiate tumor chemosensitivity by interfering with another cellular metabolic pathway has been reported through in vitro and in vivo studies by Takam Kamga et al. (2018) who showed that Notch4 inhibition increases B-ALL sensitivity to the chemotherapeutic agent ara-C by upregulating the intracellular levels of ROS, which in turn, regulate mTOR, NF- $\kappa \mathrm{B}$, and ERK expression (Takam Kamga et al., 2018). Also, the same group showed the involvement of Notch3 and Notch4 in the pathological communication between B-ALL cells and the stromal microenvironment resulting in reduced drug sensitivity (Nwabo Kamdje et al., 2011).

The evident importance of the glycolytic switch in drug resistance development suggests that targeting cancer metabolism can be effective in restoring apoptosis competence in tumor cells. Growing evidence suggests that the metabolic reprogramming of cancer cells also depends on the interaction with the surrounding microenvironment and might be disrupted by inhibiting the pathological communication mediated by Notch signaling.

\section{NOTCH ACTIVITY IS INVOLVED IN THE MAINTENANCE AND EXPANSION OF CANCER STEM CELLS}

Cancer stem cells play a key role in the development of drug resistance, that crucially contributes to determine patient's relapse and death (Phi et al., 2018). The characteristic resilience of CSCs to chemotherapeutic agents is due to different features. Indeed, (1) CSCs represent a reservoir of quiescent cells that undergo rare cellular division to maintain the bulk cell population, thereby resulting insensitive to anti-blastic treatment. (2) CSCs may efficiently extrude drugs through efflux pumps, including ABCB1, ABCG2, and ABCC1 (Moitra, 2015), (3) CSCs express high levels of detoxifying enzymes, such as ALDH (Nakahata et al., 2015), and (4) are characterized by a high anti-apoptotic 
background that hampers cell death upon treatment with proapoptotic drugs (Prieto-Vila et al., 2017; Phi et al., 2018).

These mechanisms of drug resistance can be promoted by the ability of different BM cellular players (i.e., BMSCs and OBLs) to activate pathways which allow CSCs to endure chemotherapy, survive as minimal residual disease and eventually prevail at relapse (Shiozawa and Taichman, 2012).

Here, we will explore Notch pathway ability to promote CSC self-renewal in several malignancies (Figure 1D), including T-ALL (Armstrong et al., 2009), CML (Aljedai et al., 2015), MM (Gao et al., 2016), OS (Mu et al., 2013), breast (Harrison et al., 2010a), prostate (Lin et al., 2018), and lung cancer (Hassan et al., 2013; Sosa Iglesias et al., 2018), and will report recent lines of evidence indicating that Notch signaling stimulates CSC crosstalk with the surrounding milieu resulting in a supportive feedback (Colombo et al., 2015b; Meurette and Mehlen, 2018).

In OS, Notch activation is associated with the expression of a CSCs marker, ALDH (Mu et al., 2013), whose detoxifying activity promotes cancer cell drug resistance (Honoki et al., 2010); while miR-26a inhibits CSC self-renewal ability and promotes chemosensitivity by suppressing Jagged1/Notch signaling (Lu J. et al., 2017).

Notch has been hypothesized to play a key role also in myeloma CSC maintenance (Colombo et al., 2015a). Indeed, Jagged2 expression in MM cell lines correlates with clonogenic ability and Notch-Fc chimeric molecules, uncoupling JaggedNotch interaction, reducing colony formation in vitro and tumor formation in immunocompromised mice (Chiron et al., 2012). Concerning the microenvironment involvement, Notch signaling may be triggered also by BMSC-derived Dll1, resulting in increased MM cell clonogenic growth in vitro and tumor burden in 5T33MM syngeneic murine model (Xu et al., 2012b).

Also, leukemia stem cells (LSCs) rely on BM microenvironment to survive and propagate the bulk cell population (Povinelli et al., 2018). Aljedai et al. (2015) found a significant upregulation of Notch1, Notch2 and the Notch-target gene HES1 in the most primitive $\mathrm{CD} 34^{+} \mathrm{Thy}^{+}$subset of CML stem cells, suggesting that Notch pathway activation is critical for LSC population expansion. Interestingly, Notch activation results in imatinib resistance due to the activation of the compensatory $\mathrm{PI} 3 \mathrm{~K}-\mathrm{Akt} / \mathrm{mTOR}$ pathway, finally resulting in BCR/ABL-positive cells persistence that could be prevented by the combined inhibition of Notch and BCR-ABL (Aljedai et al., 2015).

In T-ALL, Notch1 activation promotes the growth and survival of the bulk cancer cell population along with LSCs selfrenewal, as demonstrated by GSI inhibitory effect on cancer cell survival and the engraftment efficiency of primary human T-ALL cells in serial transplantation using immunocompromised mice (Belmonte et al., 2016). Moreover, T-ALL primary samples carrying mutated Notch1 showed a higher LSCs frequency and consequently an increased serial transplantation capacity in vivo respect to samples expressing the wild type form (Ma et al., 2012).

In solid tumors, Notch promotes CSCs self-renewal as well as EMT. This is of crucial importance, since EMT is closely associated to stemness and the activation of this program in malignant cells enables their conversion into CSCs, allowing them to form metastases and acquire drug resistance (Shibue and Weinberg, 2017). This connection is particularly evident in prostate cancer. Here, Notch4 activates NF- $\mathrm{kB}$, boosting cancer cells growth and EMT (Lin et al., 2018); Notch1 promotes EMT, invasion and cell migration and EMT-like prostate cancer cells display a CSC phenotype (Zhang L. et al., 2017).

Notch receptors, including Notch1, 3 , and 4, and the Jagged 1 ligand support the expansion of CSCs and the development of drug resistance also in breast cancer. In HER2 ${ }^{+}$breast cancer, Notch signaling is associated to CSC resistance to the small molecule inhibitor of HER2, Lapatinib. This promotes Jagged 1 expression in HER2 ${ }^{+}$CSCs, which, in turn, is associated with increased levels of Notch receptor expression and activity and CSCs enrichment in vitro and in vivo. Jagged1 predicts a poor overall survival (Shah et al., 2018) and is associated with bone metastasis (Zheng et al., 2017). Interestingly, in bone metastatic breast cancer, OBL-derived Jagged1 may induce drug resistance in tumor cells (Zheng et al., 2017). Other lines of evidence indicate that $\mathrm{ESA}^{+} / \mathrm{CD} 44^{+} / \mathrm{CD} 24^{\text {low }}$ breast CSCs showed high levels of Notch1 and Notch4, although Notch4 blockade was more effective in inhibiting tumor initiation in vivo (Harrison et al., 2010a,b).

In bone metastasis of luminal breast cancer, resistance to hormonal therapy is driven by a pool of self-renewing CD133 high/ER low/IL6high CSCs. High IL-6 levels stimulate Notch3 expression, that can replace the estrogen receptor signaling and promote CSCs survival and self-renewal (Sansone et al., 2016). In therapy-resistant stromal-tumor niches, IL-6/STAT3 signaling drives the expansion of BMSCs, that, in turn, secrete extracellular vesicles containing onco-miR221, able to induce hormonal therapy resistance through the generation of Notch $3^{\text {high }} / \mathrm{ER}^{\text {low }} / \mathrm{CD} 133^{\text {high }}$ CSCs (Sansone et al., 2017). Finally, Notch signaling positively regulates also NSCLC CSCs. Indeed, Notch 1 mutations present in $10 \%$ of lung cancers, are associated with poor prognosis (Westhoff et al., 2009) and promote tumor initiation (Baumgart et al., 2015). Additionally, high levels of Notch1 may be induced in NSCLC CSCs by specific environmental conditions, such as tumor associated hypoxia (Zhang Y. et al., 2017). The hypoxic condition of BM and the availability of Notch ligands expressed by BM cells (Bertrand et al., 2000; Nefedova et al., 2004; Xu et al., 2012a; Jitschin et al., 2015; Colombo et al., 2016; Sato et al., 2016) suggest that Notch1 activation is not a limiting step in BM, and interestingly Notch1 activation promotes NSCLC CSC self-renewal via p-STAT3 and HES1 and induces resistance to cis-platinum treatment through the survival regulators $\mathrm{p}-\mathrm{AKT}$ and survivin in a HES1-independent manner (Zhang Y. et al., 2017).

\section{CONCLUSION}

We believe that the lines of evidence here reported and summarized in Table $\mathbf{1}$ clearly show that Notch signaling is instrumental in the pathological communication between tumor cells and $\mathrm{BM}$ leading to the reprogramming of surrounding microenvironment and the development of pharmacological resistance. Thus, targeting Notch pathway to prevent BMmediated support promises to be effective in re-establishing 
apoptosis competence and overcoming drug resistance to eradicate the disease. Notably, although the important side effects of the currently used pan-Notch signaling inhibitors on small intestine, our survey points out that several tumors establish an aberrant communication with the surrounding microenvironment exploiting only one or few components of the pathway, thereby suggesting that a safer use is possible using the inhibitors specific for a single receptor or ligand recently developed (Wu et al., 2010; Platonova et al., 2017b).

\section{AUTHOR CONTRIBUTIONS}

$\mathrm{RC}$ and $\mathrm{AB}$ conceived, designed, and drafted the manuscript. MC, NP, and DG wrote sections of the manuscript. MTP drew

\section{REFERENCES}

Aljedai, A., Buckle, A. M., Hiwarkar, P., and Syed, F. (2015). Potential role of notch signalling in CD34+ chronic myeloid leukaemia cells: cross-talk between Notch and BCR-ABL. PLoS One 10:e0123016. doi: 10.1371/journal.pone.0123016

Ara, T., and Declerck, Y. A. (2010). Interleukin-6 in bone metastasis and cancer progression. Eur. J. Cancer 46, 1223-1231. doi: 10.1016/j.ejca.2010.02.026

Armstrong, F., Brunet de la Grange, P., Gerby, B., Rouyez, M. C., Calvo, J., Fontenay, M., et al. (2009). Notch is a key regulator of human T-cell acute leukemia initiating cell activity. Blood 113, 1730-1740. doi: 10.1182/blood2008-02-138172

Ayaz, F., and Osborne, B. A. (2014). Non-canonical notch signaling in cancer and immunity. Front. Oncol. 4:345. doi: 10.3389/fonc.2014.00345

Baumgart, A., Mazur, P. K., Anton, M., Rudelius, M., Schwamborn, K., Feuchtinger, A., et al. (2015). Opposing role of Notch1 and Notch2 in a Kras(G12D)-driven murine non-small cell lung cancer model. Oncogene 34, 578-588. doi: 10.1038/onc.2013.592

Behrmann, L., Wellbrock, J., and Fiedler, W. (2018). Acute myeloid leukemia, and the bone marrow niche-take a closer look. Front. Oncol. 8:444. doi: 10.3389/ fonc.2018.00444

Belcheva, A., Wey, J. S., Fan, F., and Ellis, L. M. (2004). Expression of vascular endothelial growth factor receptors (VEGF-Rs) on human breast cancer cells confers chemoresistance. Cancer Res. 64(7 Suppl.):1000.

Belmonte, M., Hoofd, C., Weng, A. P., and Giambra, V. (2016). Targeting leukemia stem cells: which pathways drive self-renewal activity in T-cell acute lymphoblastic leukemia? Curr. Oncol. 23, 34-41. doi: 10.3747/co.23.2806

Bendardaf, R., El-Serafi, A., Syrjanen, K., Collan, Y., and Pyrhonen, S. (2017). The effect of vascular endothelial growth factor-1 expression on survival of advanced colorectal cancer patients. Libyan J. Med. 12:1290741. doi: 10.1080/19932820. 2017.1290741

Bertrand, F. E., Eckfeldt, C. E., Lysholm, A. S., and LeBien, T. W. (2000). Notch1 and Notch-2 exhibit unique patterns of expression in human B-lineage cells. Leukemia 14, 2095-2102. doi: 10.1038/sj.leu.2401942

Butler, E. B., Zhao, Y., Muñ;oz-Pinedo, C., Lu, J., and Tan, M. (2013). Stalling the engine of resistance: targeting cancer metabolism to overcome therapeutic resistance. Cancer Res. 73, 2709-2717. doi: 10.1158/0008-5472.can-12-3009

Catlett-Falcone, R., Landowski, T. H., Oshiro, M. M., Turkson, J., Levitzki, A., Savino, R., et al. (1999). Constitutive activation of Stat3 signaling confers resistance to apoptosis in human U266 myeloma cells. Immunity 10, 105-115. doi: 10.1016/S1074-7613(00)80011-4

Chiron, D., Maiga, S., Descamps, G., Moreau, P., Le Gouill, S., Marionneau, S., et al. (2012). Critical role of the NOTCH ligand JAG2 in self-renewal of myeloma cells. Blood Cells Mol. Dis. 48, 247-253. doi: 10.1016/j.bcmd.2012.01.006

Coleman, R. E. (2006). Clinical features of metastatic bone disease and risk of skeletal morbidity. Clin. Cancer Res. 12(20 Pt 2), 6243s-6249s. doi: 10.1158/ 1078-0432.CCR-06-0931

Colombo, M., Galletti, S., Bulfamante, G., Falleni, M., Tosi, D., Todoerti, K., et al. (2016). Multiple myeloma-derived jagged ligands increases autocrine the figures and wrote figure legends. All authors contributed to manuscript revision, read and approved the submitted version.

\section{FUNDING}

This study was supported by grants from Associazione Italiana per la Ricerca sul Cancro (Investigator grant 20614) and from Università degli Studi di Milano (Linea 2B-2017 - Department of Health Sciences) to RC, Fondazione Italiana per la Ricerca sul Cancro to MC (post-doctoral fellowship 18013), Università degli Studi di Milano to NP (post-doctoral fellowship type A), MTP (fellowship from the Ph.D. program in Molecular and Translational Medicine), and DG (fellowship from the Ph.D. program in Experimental Medicine).

and paracrine interleukin-6 expression in bone marrow niche. Oncotarget 7, 56013-56029. doi: 10.18632/oncotarget.10820

Colombo, M., Galletti, S., Garavelli, S., Platonova, N., Paoli, A., Basile, A., et al. (2015a). Notch signaling deregulation in multiple myeloma: a rational molecular target. Oncotarget 6, 26826-26840. doi: 10.18632/oncotarget.5025

Colombo, M., Mirandola, L., Reidy, A., Suvorava, N., Konala, V., Chiaramonte, R., et al. (2015b). Targeting tumor initiating cells through inhibition of cancer testis antigens and notch signaling: a hypothesis. Int. Rev. Immunol. 34, 188-199. doi: 10.3109/08830185.2015.1027629

Colombo, M., Mirandola, L., Chiriva-Internati, M., Basile, A., Locati, M., Lesma, E., et al. (2018). Cancer cells exploit notch signaling to redefine a supportive cytokine milieu. Front. Immunol. 9:1823. doi: 10.3389/fimmu.2018.01823

Colombo, M., Mirandola, L., Platonova, N., Apicella, L., Basile, A., Figueroa, A. J., et al. (2013). Notch-directed microenvironment reprogramming in myeloma: a single path to multiple outcomes. Leukemia 27, 1009-1018. doi: 10.1038/leu. 2013.6

Colombo, M., Thummler, K., Mirandola, L., Garavelli, S., Todoerti, K., Apicella, L., et al. (2014). Notch signaling drives multiple myeloma induced osteoclastogenesis. Oncotarget 5, 10393-10406. doi: 10.18632/oncotarget.2084

Crews, L. A., and Jamieson, C. H. (2012). Chronic myeloid leukemia stem cell biology. Curr. Hematol. Malig. Rep. 7, 125-132. doi: 10.1007/s11899-0120121-6

Dang, C. V., Le, A., and Gao, P. (2009). MYC-induced cancer cell energy metabolism and therapeutic opportunities. Clin. Cancer Res. 15, 6479-6483. doi: 10.1158/1078-0432.CCR-09-0889

Dias, S., Choy, M., Alitalo, K., and Rafii, S. (2002). Vascular endothelial growth factor (VEGF)-C signaling through FLT-4 (VEGFR-3) mediates leukemic cell proliferation, survival, and resistance to chemotherapy. Blood 99, 2179-2184. doi: 10.1182/blood.V99.6.2179

Diedrich, J. D., Rajagurubandara, E., Herroon, M. K., Mahapatra, G., Huttemann, M., and Podgorski, I. (2016). Bone marrow adipocytes promote the Warburg phenotype in metastatic prostate tumors via HIF-1alpha activation. Oncotarget 7, 64854-64877. doi: 10.18632/oncotarget.11712

Ding, Y., and Shen, Y. (2015). Notch increased vitronection adhesion protects myeloma cells from drug induced apoptosis. Biochem. Biophys. Res. Commun. 467, 717-722. doi: 10.1016/j.bbrc.2015.10.076

Frolova, O., Samudio, I., Benito, J. M., Jacamo, R., Kornblau, S. M., Markovic, A., et al. (2012). Regulation of HIF-1alpha signaling and chemoresistance in acute lymphocytic leukemia under hypoxic conditions of the bone marrow microenvironment. Cancer Biol. Ther. 13, 858-870. doi: 10.4161/cbt. 20838

Gao, M., Kong, Y., Yang, G., Gao, L., and Shi, J. (2016). Multiple myeloma cancer stem cells. Oncotarget 7, 35466-35477. doi: 10.18632/oncotarget. 8154

Garavelli, S., Lazzari, E., Colombo, M., Platonova, N., Palano, M. T., Baccianti, F., et al. (2017). The role of notch pathway in multiple myeloma associated drug resistance. Cancer Res. 77(13 Suppl.), AbstractnrLB-025. doi: 10.1158/15387445 
Gerber, H. P., Dixit, V., and Ferrara, N. (1998). Vascular endothelial growth factor induces expression of the antiapoptotic proteins $\mathrm{Bcl}-2$ and $\mathrm{A} 1$ in vascular endothelial cells. J. Biol. Chem. 273, 13313-13316. doi: 10.1074/jbc.273.21.13313

Harrison, H., Farnie, G., Brennan, K. R., and Clarke, R. B. (2010a). Breast cancer stem cells: something out of notching? Cancer Res. 70, 8973-8976. doi: 10.1158/ 0008-5472.can-10-1559

Harrison, H., Farnie, G., Howell, S. J., Rock, R. E., Stylianou, S., Brennan, K. R., et al. (2010b). Regulation of breast cancer stem cell activity by signaling through the Notch4 receptor. Cancer Res. 70, 709-718. doi: 10.1158/0008-5472.can-09-1681

Hassan, K. A., Wang, L., Korkaya, H., Chen, G., Maillard, I., Beer, D. G., et al. (2013). Notch pathway activity identifies cells with cancer stem cell-like properties and correlates with worse survival in lung adenocarcinoma. Clin. Cancer Res. 19, 1972-1980. doi: 10.1158/1078-0432.ccr-12-0370

Honoki, K., Fujii, H., Kubo, A., Kido, A., Mori, T., Tanaka, Y., et al. (2010). Possible involvement of stem-like populations with elevated ALDH1 in sarcomas for chemotherapeutic drug resistance. Oncol. Rep. 24, 501-505. doi: 10.3892/or 00000885

Houde, C., Li, Y., Song, L., Barton, K., Zhang, Q., Godwin, J., et al. (2004). Overexpression of the NOTCH ligand JAG2 in malignant plasma cells from multiple myeloma patients and cell lines. Blood 104, 3697-3704. doi: 10.1182/ blood-2003-12-4114

Hua, K. T., Lee, W. J., Yang, S. F., Chen, C. K., Hsiao, M., Ku, C. C., et al. (2014). Vascular endothelial growth factor-C modulates proliferation and chemoresistance in acute myeloid leukemic cells through an endothelin-1dependent induction of cyclooxygenase-2. Biochim. Biophys. Acta 1843, 387397. doi: 10.1016/j.bbamcr.2013.10.015

Huang, X. Q., Chen, X., Xie, X. X., Zhou, Q., Li, K., Li, S., et al. (2014). Coexpression of CD147 and GLUT-1 indicates radiation resistance and poor prognosis in cervical squamous cell carcinoma. Int. J. Clin. Exp. Pathol. 7, 1651-1666.

Jitschin, R., Braun, M., Qorraj, M., Saul, D., Le Blanc, K., Zenz, T., et al. (2015). Stromal cell-mediated glycolytic switch in CLL cells involves Notch-c-Myc signaling. Blood 125, 3432-3436. doi: 10.1182/blood-2014-10607036

Jundt, F., Anagnostopoulos, I., Forster, R., Mathas, S., Stein, H., and Dorken, B. (2002). Activated Notch1 signaling promotes tumor cell proliferation and survival in hodgkin and anaplastic large cell lymphoma. Blood 99, 3398-3403. doi: 10.1182/blood.V99.9.3398

Kageyama, R., Ohtsuka, T., and Kobayashi, T. (2007). The Hes gene family: repressors and oscillators that orchestrate embryogenesis. Development 134, 1243-1251. doi: 10.1242/dev.000786

Kan, C., Vargas, G., Pape, L. F., and Clézardin, P. (2016). Cancer cell colonisation in the bone microenvironment. Int. J. Mol. Sci. 17:1674. doi: 10.3390/ ijms17101674

Kontomanolis, E. N., Kalagasidou, S., Pouliliou, S., Anthoulaki, X., Georgiou, N., Papamanolis, V., et al. (2018). The notch pathway in breast cancer progression. Sci. World J. 2018:2415489. doi: 10.1155/2018/2415489

Koppenol, W. H., Bounds, P. L., and Dang, C. V. (2011). Otto Warburg's contributions to current concepts of cancer metabolism. Nat. Rev. Cancer 11, 325-337. doi: 10.1038/nrc3038

Kuhn, D. J., Berkova, Z., Jones, R. J., Woessner, R., Bjorklund, C. C., Ma, W., et al. (2012). Targeting the insulin-like growth factor-1 receptor to overcome bortezomib resistance in preclinical models of multiple myeloma. Blood 120, 3260-3270. doi: 10.1182/blood-2011-10-386789

Lamy, M., Ferreira, A., Dias, J. S., Braga, S., Silva, G., and Barbas, A. (2017). Notch-out for breast cancer therapies. New Biotechnol. 39(Pt B), 215-221. doi: 10.1016/j.nbt.2017.08.004

Landor, S. K., Mutvei, A. P., Mamaeva, V., Jin, S., Busk, M., Borra, R., et al. (2011). Hypo- and hyperactivated Notch signaling induce a glycolytic switch through distinct mechanisms. Proc. Natl. Acad. Sci. U.S.A. 108, 18814-18819. doi: 10.1073/pnas.1104943108

Lin, C. J., Lo, U. G., and Hsieh, J. T. (2018). The regulatory pathways leading to stem-like cells underlie prostate cancer progression. Asian J. Androl. doi: 10.4103/aja.aja_72_18 [Epub ahead of print].

Lin, Y., Lv, F., Liu, F., Guo, X., Fan, Y., Gu, F., et al. (2015). High expression of pyruvate kinase M2 is associated with chemosensitivity to epirubicin and 5-fluorouracil in breast cancer. J. Cancer 6, 1130-1139. doi: 10.7150/jca.12719
Lu, J., Song, G., Tang, Q., Yin, J., Zou, C., Zhao, Z., et al. (2017). MiR-26a inhibits stem cell-like phenotype and tumor growth of osteosarcoma by targeting Jagged1. Oncogene 36, 231-241. doi: 10.1038/onc.2016.194

Lu, J., Tan, M., and Cai, Q. (2015). The warburg effect in tumor progression: mitochondrial oxidative metabolism as an anti-metastasis mechanism. Cancer Lett. 356(2 Pt A), 156-164. doi: 10.1016/j.canlet.2014.04.001

Lu, W. Q., Hu, Y. Y., Lin, X. P., and Fan, W. (2017). Knockdown of PKM2 and GLS1 expression can significantly reverse oxaliplatin-resistance in colorectal cancer cells. Oncotarget 8, 44171-44185. doi: 10.18632/oncotarget.17396

Ma, W., Gutierrez, A., Goff, D. J., Geron, I., Sadarangani, A., Jamieson, C. A., et al. (2012). NOTCH1 signaling promotes human T-cell acute lymphoblastic leukemia initiating cell regeneration in supportive niches. PLoS One 7:e39725. doi: 10.1371/journal.pone.0039725

Ma, Y., Ren, Y., Han, E. Q., Li, H., Chen, D., Jacobs, J. J., et al. (2013). Inhibition of the Wnt-beta-catenin and Notch signaling pathways sensitizes osteosarcoma cells to chemotherapy. Biochem. Biophys. Res. Commun. 431, 274-279. doi: 10.1016/j.bbrc.2012.12.118

Macedo, F., Ladeira, K., Pinho, F., Saraiva, N., Bonito, N., Pinto, L., et al. (2017). Bone metastases: an overview. Oncol. Rev. 11:321. doi: 10.4081/oncol.2017.321

MacKenzie, F., Duriez, P., Wong, F., Noseda, M., and Karsan, A. (2004). Notch4 inhibits endothelial apoptosis via RBP-Jkappa-dependent and -independent pathways. J. Biol. Chem. 279, 11657-11663. doi: 10.1074/jbc.M312102200

McManus, M. M., Weiss, K. R., and Hughes, D. P. (2014). Understanding the role of Notch in osteosarcoma. Adv. Exp. Med. Biol. 804, 67-92. doi: 10.1007/978-3319-04843-7_4

Meng, R. D., Shelton, C. C., Li, Y. M., Qin, L. X., Notterman, D., Paty, P. B., et al. (2009). gamma-Secretase inhibitors abrogate oxaliplatin-induced activation of the Notch-1 signaling pathway in colon cancer cells resulting in enhanced chemosensitivity. Cancer Res. 69, 573-582. doi: 10.1158/0008-5472.CAN-082088

Meurette, O., and Mehlen, P. (2018). Notch signaling in the tumor microenvironment. Cancer Cell 34, 536-548. doi: 10.1016/j.ccell.2018.07.009

Meurette, O., Stylianou, S., Rock, R., Collu, G. M., Gilmore, A. P., and Brennan, K. (2009). Notch activation induces Akt signaling via an autocrine loop to prevent apoptosis in breast epithelial cells. Cancer Res. 69, 5015-5022. doi: 10.1158/ 0008-5472.CAN-08-3478

Mirandola, L., Apicella, L., Colombo, M., Yu, Y., Berta, D. G., Platonova, N., et al. (2013). Anti-Notch treatment prevents multiple myeloma cells localization to the bone marrow via the chemokine system CXCR4/SDF-1. Leukemia 27, 1558-1566. doi: 10.1038/leu.2013.27

Moitra, K. (2015). Overcoming multidrug resistance in cancer stem cells. Biomed Res. Int. 2015:635745. doi: 10.1155/2015/635745

Mu, X., Isaac, C., Greco, N., Huard, J., and Weiss, K. (2013). Notch signaling is associated with ALDH activity and an aggressive metastatic phenotype in murine osteosarcoma cells. Front. Oncol. 3:143. doi: 10.3389/fonc.2013.00143

Muguruma, Y., Yahata, T., Warita, T., Hozumi, K., Nakamura, Y., Suzuki, R., et al. (2017). Jagged1-induced Notch activation contributes to the acquisition of bortezomib resistance in myeloma cells. Blood Cancer J. 7:650. doi: 10.1038/ s41408-017-0001-3

Mundy, G. R. (2002). Metastasis to bone: causes, consequences and therapeutic opportunities. Nat. Rev. Cancer 2, 584-593. doi: 10.1038/nrc867

Nakahata, K., Uehara, S., Nishikawa, S., Kawatsu, M., Zenitani, M., Oue, T., et al. (2015). Aldehyde Dehydrogenase 1 (ALDH1) Is a potential marker for cancer stem cells in embryonal rhabdomyosarcoma. PLoS One 10:e0125454. doi: 10.1371/journal.pone.0125454

Nefedova, Y., Cheng, P., Alsina, M., Dalton, W. S., and Gabrilovich, D. I. (2004). Involvement of Notch-1 signaling in bone marrow stroma-mediated de novo drug resistance of myeloma and other malignant lymphoid cell lines. Blood 103, 3503-3510. doi: 10.1182/blood-2003-07-2340

Nefedova, Y., Sullivan, D. M., Bolick, S. C., Dalton, W. S., and Gabrilovich, D. I. (2008). Inhibition of Notch signaling induces apoptosis of myeloma cells and enhances sensitivity to chemotherapy. Blood 111, 2220-2229. doi: 10.1182/ blood-2007-07-102632

Nusrat, O., Belotte, J., Fletcher, N. M., Memaj, I., Saed, M. G., Diamond, M. P., et al. (2016). The role of angiogenesis in the persistence of chemoresistance in epithelial ovarian cancer. Reprod. Sci. 23, 1484-1492. doi: 10.1177/ 1933719116645191 
Nwabo Kamdje, A. H., Bassi, G., Pacelli, L., Malpeli, G., Amati, E., Nichele, I., et al. (2012). Role of stromal cell-mediated Notch signaling in CLL resistance to chemotherapy. Blood Cancer J. 2:e73. doi: 10.1038/bcj.2012.17

Nwabo Kamdje, A. H., Mosna, F., Bifari, F., Lisi, V., Bassi, G., Malpeli, G., et al. (2011). Notch-3 and Notch-4 signaling rescue from apoptosis human B-ALL cells in contact with human bone marrow-derived mesenchymal stromal cells. Blood 118, 380-389. doi: 10.1182/blood-2010-12-326694

Perumalsamy, L. R., Nagala, M., Banerjee, P., and Sarin, A. (2009). A hierarchical cascade activated by non-canonical Notch signaling and the mTOR-Rictor complex regulates neglect-induced death in mammalian cells. Cell Death Differ. 16, 879-889. doi: 10.1038/cdd.2009.20

Phi, L. T. H., Sari, I. N., Yang, Y. G., Lee, S. H., Jun, N., Kim, K. S., et al. (2018). Cancer Stem Cells (CSCs) in drug resistance and their therapeutic implications in cancer treatment. Stem Cells Int. 2018:5416923. doi: 10.1155/2018/5416923

Platonova, N., Lesma, E., Basile, A., Bignotto, M., Garavelli, S., Palano, M. T., et al. (2017a). Targeting Notch as a therapeutic approach for human malignancies. Curr. Pharm. Des. 23, 108-134. doi: 10.2174/1381612822666161006160524

Platonova, N., Manzo, T., Mirandola, L., Colombo, M., Calzavara, E., Vigolo, E., et al. (2015). PI3K/AKT signaling inhibits NOTCH1 lysosome-mediated degradation. Genes Chromosomes Cancer 54, 516-526. doi: 10.1002/gcc.22264

Platonova, N., Parravicini, C., Sensi, C., Paoli, A., Colombo, M., Neri, A., et al. (2017b). Identification of small molecules uncoupling the Notch: jagged interaction through an integrated high-throughput screening. PLoS One 12:e0182640. doi: 10.1371/journal.pone.0182640

Povinelli, B. J., Rodriguez-Meira, A., and Mead, A. J. (2018). Single cell analysis of normal and leukemic hematopoiesis. Mol. Aspects Med. 59, 85-94. doi: 10.1016/ j.mam.2017.08.006

Prieto-Vila, M., Takahashi, R. U., Usuba, W., Kohama, I., and Ochiya, T. (2017). Drug resistance driven by cancer stem cells and their niche. Int. J. Mol. Sci. 18:2574. doi: 10.3390/ijms18122574

Pu, Y., Zhao, F., Wang, H., and Cai, S. (2017). MiR-34a-5p promotes multichemoresistance of osteosarcoma through down-regulation of the DLL1 gene. Sci. Rep. 7:44218. doi: 10.1038/srep44218

Rangarajan, A., Talora, C., Okuyama, R., Nicolas, M., Mammucari, C., Oh, H., et al. (2001). Notch signaling is a direct determinant of keratinocyte growth arrest and entry into differentiation. EMBO J. 20, 3427-3436. doi: 10.1093/emboj/20. 13.3427

Ronchini, C., and Capobianco, A. J. (2001). Induction of cyclin D1 transcription and CDK2 activity by Notch(ic): implication for cell cycle disruption in transformation by Notch(ic). Mol. Cell Biol. 21, 5925-5934. doi: 10.1128/MCB. 21.17.5925-5934.2001

Rosati, E., Baldoni, S., De Falco, F., Del Papa, B., Dorillo, E., Rompietti, C., et al. (2018). Notch1 aberrations in Chronic Lymphocytic Leukemia. Front. Oncol. 8:229. doi: $10.3389 /$ fonc. 2018.00229

Sade, H., Krishna, S., and Sarin, A. (2004). The anti-apoptotic effect of Notch1 requires p56lck-dependent, Akt/PKB-mediated signaling in T cells. J. Biol. Chem. 279, 2937-2944. doi: 10.1074/jbc.M309924200

Sansone, P., Berishaj, M., Rajasekhar, V. K., Ceccarelli, C., Chang, Q., Strillacci, A., et al. (2017). Evolution of cancer stem-like cells in endocrine-resistant metastatic breast cancers is mediated by stromal microvesicles. Cancer Res. 77, 1927-1941. doi: 10.1158/0008-5472.can-16-2129

Sansone, P., Ceccarelli, C., Berishaj, M., Chang, Q., Rajasekhar, V. K., Perna, F., et al. (2016). Self-renewal of CD133hi cells by IL6/Notch3 signalling regulates endocrine resistance in metastatic breast cancer. Nat. Commun. 7:10442. doi: 10.1038/ncomms 10442

Sato, Y., Mabuchi, Y., Miyamoto, K., Araki, D., Niibe, K., Houlihan, D. D., et al. (2016). Notch2 signaling regulates the proliferation of murine bone marrow-derived mesenchymal stem/stromal cells via c-Myc expression. PLoS One 11:e0165946. doi: 10.1371/journal.pone.0165946

Secchiero, P., Voltan, R., Rimondi, E., Melloni, E., Athanasakis, E., Tisato, V., et al. (2017). The gamma-secretase inhibitors enhance the anti-leukemic activity of ibrutinib in B-CLL cells. Oncotarget 8, 59235-59245. doi: 10.18632/oncotarget. 19494

Sethi, N., Dai, X., Winter, C. G., and Kang, Y. (2011). Tumor-derived JAGGED1 promotes osteolytic bone metastasis of breast cancer by engaging notch signaling in bone cells. Cancer Cell 19, 192-205. doi: 10.1016/j.ccr.2010.12.022

Shah, D., Wyatt, D., Baker, A. T., Simms, P., Peiffer, D. S., Fernandez, M., et al. (2018). Inhibition of HER2 increases JAGGED1-dependent breast cancer stem cells: role for membrane JAGGED1. Clin. Cancer Res. 24, 4566-4578. doi: 10. 1158/1078-0432.ccr-17-1952

Shain, K. H., Yarde, D. N., Meads, M. B., Huang, M., Jove, R., Hazlehurst, L. A., et al. (2009). Betal integrin adhesion enhances IL-6-mediated STAT3 signaling in myeloma cells: implications for microenvironment influence on tumor survival and proliferation. Cancer Res. 69, 1009-1015. doi: 10.1158/0008-5472.CAN-082419

Shibue, T., and Weinberg, R. A. (2017). EMT, CSCs, and drug resistance: the mechanistic link and clinical implications. Nat. Rev. Clin. Oncol. 14, 611-629. doi: 10.1038/nrclinonc.2017.44

Shiozawa, Y., and Taichman, R. S. (2012). Cancer stem cells and the bone marrow microenvironment. Bonekey Rep. 1:48. doi: 10.1038/bonekey.2012.48

Siebel, C., and Lendahl, U. (2017). Notch signaling in development, tissue homeostasis, and disease. Physiol. Rev. 97, 1235-1294. doi: 10.1152/physrev. 00005.2017

Skrtic, A., Korac, P., Kristo, D. R., Ajdukovic Stojisavljevic, R., Ivankovic, D., and Dominis, M. (2010). Immunohistochemical analysis of Notchl and Jagged1 expression in multiple myeloma and monoclonal gammopathy of undetermined significance. Hum. Pathol. 41, 1702-1710. doi: 10.1016/j. humpath.2010.05.002

Slaninova, V., Krafcikova, M., Perez-Gomez, R., Steffal, P., Trantirek, L., Bray, S. J., et al. (2016). Notch stimulates growth by direct regulation of genes involved in the control of glycolysis and the tricarboxylic acid cycle. Open Biol. 6:150155. doi: 10.1098/rsob.150155

Sosa Iglesias, V., Giuranno, L., Dubois, L. J., Theys, J., and Vooijs, M. (2018). Drug resistance in non-small cell lung cancer: a potential for Notch Targeting? Front. Oncol. 8:267. doi: 10.3389/fonc.2018.00267

Sun, H., Zhu, A., Zhou, X., and Wang, F. (2017). Suppression of pyruvate dehydrogenase kinase-2 re-sensitizes paclitaxel-resistant human lung cancer cells to paclitaxel. Oncotarget 8, 52642-52650. doi: 10.18632/oncotarget.16991

Takam Kamga, P., Bassi, G., Cassaro, A., Midolo, M., Di Trapani, M., Gatti, A., et al. (2016). Notch signalling drives bone marrow stromal cell-mediated chemoresistance in acute myeloid leukemia. Oncotarget 7, 21713-21727. doi: 10.18632/oncotarget.7964

Takam Kamga, P., Dal Collo, G., Midolo, M., Adamo, A., Delfino, P., Mercuri, A., et al. (2018). Inhibition of Notch signaling enhances chemosensitivity in B cell precursor acute lymphoblastic leukemia. Cancer Res. 79, 639-649. doi: 10.1158/ 0008-5472.CAN-18-1617

Tao, J., Jiang, M. M., Jiang, L., Salvo, J. S., Zeng, H. C., Dawson, B., et al. (2014). Notch activation as a driver of osteogenic sarcoma. Cancer Cell 26, 390-401. doi: 10.1016/j.ccr.2014.07.023

Tran, J., Master, Z., Yu, J. L., Rak, J., Dumont, D. J., and Kerbel, R. S. (2002). A role for survivin in chemoresistance of endothelial cells mediated by VEGF. Proc. Natl. Acad. Sci. U.S.A. 99, 4349-4354. doi: 10.1073/pnas.072586399

Vangapandu, H. V., Ayres, M. L., Bristow, C. A., Wierda, W. G., Keating, M. J., Balakrishnan, K., et al. (2017). The stromal microenvironment modulates mitochondrial oxidative phosphorylation in Chronic Lymphocytic Leukemia cells. Neoplasia 19, 762-771. doi: 10.1016/j.neo.2017.07.004

Vilimas, T., Mascarenhas, J., Palomero, T., Mandal, M., Buonamici, S., Meng, F., et al. (2007). Targeting the NF-kappaB signaling pathway in Notch1-induced T-cell leukemia. Nat. Med. 13, 70-77. doi: 10.1038/nm1524

Wang, K., Zhang, Q., Li, D., Ching, K., Zhang, C., Zheng, X., et al. (2015). PEST domain mutations in Notch receptors comprise an oncogenic driver segment in triple-negative breast cancer sensitive to a gamma-secretase inhibitor. Clin. Cancer 21, 1487-1496. doi: 10.1158/1078-0432.CCR-14- 1348

Weber, D., Wiese, C., and Gessler, M. (2014). Hey bHLH transcription factors. Curr. Top Dev. Biol. 110, 285-315. doi: 10.1016/B978-0-12-405943-6. 00008-7

Westhoff, B., Colaluca, I. N., D’Ario, G., Donzelli, M., Tosoni, D., Volorio, S., et al. (2009). Alterations of the Notch pathway in lung cancer. Proc. Natl. Acad. Sci. U.S.A. 106, 22293-22298. doi: 10.1073/pnas.0907781106

Wu, Y., Cain-Hom, C., Choy, L., Hagenbeek, T. J., de Leon, G. P., Chen, Y., et al. (2010). Therapeutic antibody targeting of individual Notch receptors. Nature 464, 1052-1057. doi: 10.1038/nature08878

Xu, D., Hu, J., De Bruyne, E., Menu, E., Schots, R., Vanderkerken, K., et al. (2012a). Dll1/Notch activation contributes to bortezomib resistance by upregulating CYP1A1 in multiple myeloma. Biochem. Biophys. Res. Commun. 428, 518-524. doi: $10.1016 /$ j.bbrc.2012.10.071 
Xu, D., Hu, J., Xu, S., De Bruyne, E., Menu, E., Van Camp, B., et al. (2012b). Dll1/Notch activation accelerates multiple myeloma disease development by promoting CD138+ MM-cell proliferation. Leukemia 26, 1402-1405. doi: 10. 1038/leu.2011.332

Zhang, L., Hannay, J. A., Liu, J., Das, P., Zhan, M., Nguyen, T., et al. (2006). Vascular endothelial growth factor overexpression by soft tissue sarcoma cells: implications for tumor growth, metastasis, and chemoresistance. Cancer Res. 66, 8770-8778. doi: 10.1158/0008-5472.CAN-06-1217

Zhang, L., Sha, J., Yang, G., Huang, X., Bo, J., and Huang, Y. (2017). Activation of Notch pathway is linked with epithelial-mesenchymal transition in prostate cancer cells. Cell Cycle 16, 999-1007. doi: 10.1080/15384101.2017. 1312237

Zhang, X. Y., Zhang, M., Cong, Q., Zhang, M. X., Zhang, M. Y., Lu, Y. Y., et al. (2018). Hexokinase 2 confers resistance to cisplatin in ovarian cancer cells by enhancing cisplatin-induced autophagy. Int. J. Biochem. Cell Biol. 95, 9-16. doi: 10.1016/j.biocel.2017.12.010

Zhang, Y., Xu, W., Guo, H., He, Y., Lee, S. H., Song, X., et al. (2017). Notch1 signaling regulates self-renewal and platinum chemoresistance of cancer stemlike cells in human non-small cell lung cancer. Cancer Res. 77, 3082-3091. doi: 10.1158/0008-5472.can-16-1633
Zhao, Y., Liu, H., Liu, Z., Ding, Y., Ledoux, S. P., Wilson, G. L., et al. (2011). Overcoming trastuzumab resistance in breast cancer by targeting dysregulated glucose metabolism. Cancer Res. 71, 4585-4597. doi: 10.1158/0008-5472.CAN11-0127

Zheng, H., Bae, Y., Kasimir-Bauer, S., Tang, R., Chen, J., Ren, G., et al. (2017). Therapeutic antibody targeting tumor- and osteoblastic niche-derived jagged 1 sensitizes bone metastasis to chemotherapy. Cancer Cell 32:e6. doi: 10.1016/j. ccell.2017.11.002

Conflict of Interest Statement: The authors declare that the research was conducted in the absence of any commercial or financial relationships that could be construed as a potential conflict of interest.

Copyright (c) 2019 Colombo, Platonova, Giannandrea, Palano, Basile and Chiaramonte. This is an open-access article distributed under the terms of the Creative Commons Attribution License (CC BY). The use, distribution or reproduction in other forums is permitted, provided the original author(s) and the copyright owner(s) are credited and that the original publication in this journal is cited, in accordance with accepted academic practice. No use, distribution or reproduction is permitted which does not comply with these terms. 